\title{
Abordagem crítica da cultura da inspiração: produção de narrativas e 0 ideário da sociedade empreendedora ${ }^{1}$
}

\section{Vander Casaqui}

\section{Resumo}

No contexto contemporâneo, a inspiração é um termo recorrente, quando observamos os discursos que difundem a ideologia do empreendedorismo. Em abordagem crítica, nossa pesquisa tem como objetivo analisar o papel das narrativas inspiracionais, na publicização do ideário da "sociedade empreendedora". 0 objeto deste estudo inclui discursos de empreendedores e empreendedores sociais, palestras motivacionais, entre outros produtos midiáticos que assumem a missão de inspirar. 0 resultado desse mapeamento aponta para a cultura da inspiração como elemento chave para promover 0 engajamento dos sujeitos no capitalismo de nosso tempo, como discutem Boltanski e Chiapello (2009).

\section{Palavras-Chave}

Comunicação e consumo. Cultura da inspiração. Cultura empreendedora. Discurso.

\section{Vander Casaqui I vcasaqui@yahoo.com.br}

Doutor em Ciências da Comunicação pela Universidade de São Paulo - USP, Brasil. Pós-doutor pela Universidade Nova de Lisboa, Portugal. Professor do Programa de Pós-Graduação em Comunicação e Práticas de Consumo da Escola Superior de Propaganda e Marketing - ESPM, Brasil.

\section{Introdução}

Às vésperas da abertura da Copa do Mundo do Brasil de 2014, que foi realizada entre os meses de junho e julho, um comercial da marca global de materiais esportivos Nike, patrocinadora da seleção brasileira, desperta a atenção em meio às mensagens publicitárias que aproveitam 0 espírito da competição para capitanear afetos em torno das mercadorias que anunciam. 0 filme se apoia nas palavras extraídas de entrevista de $1990^{2}$ com ex-piloto de Fórmula 1 Ayrton Senna, falecido de forma trágica poucos anos depois, em acidente durante uma prova do campeonato de 1994 no circuito de Ímola, Itália, em transmissão ao vivo para 0 mundo todo. Esse acontecimento foi utilizado, na época, como estratégia motivacional para a seleção brasileira de futebol, que disputou e venceu a equipe italiana na final da Copa do Mundo dos EUA daquele ano. Com o objetivo de "inspirar todos os brasileiros, especialmente os atletas de todos os níveis técnicos e idades. Motivá-los a sonhar sempre, ter força de vontade, acreditar e colocar tudo em jogo, com a convicção de que 0 objetivo será alcançado", de acordo com 
matéria publicada na Revista Exame (AYRTON, 2014), o comercial da Nike mostra a imagem de jovens atletas, estáticos, olhando fixamente em direção à câmera, em sincronia com a mensagem de Ayrton (Fig. 1):

A vocês todos que assistirem e estão assistindo agora, eu digo que, seja quem você for, qualquer posição que você tenha na vida - nível altíssimo ou mais baixo, tenha sempre como meta muita força, muita determinação e, sempre, faça tudo com muito amor e com muita fé em Deus que um dia você chega lá. De alguma maneira você chega lá.

0 comercial "Chegue lá - Senna" da Nike - com mais de cinco milhões de views somente em sua postagem oficial pela Nike no Canal Youtube, no momento de elaboração deste artigo -, recupera discursos que ecoam o imaginário do batalhador brasileiro (SOUZA, 2010), arraigado na fé tornada discurso motivacional. Nesse sentido, o cenário de desigualdades de nossa sociedade, que aparece como ponto de partida do raciocínio do ídolo do esporte, é suplantado pelo mito da superação pessoal, como forma de ultrapassar qualquer obstáculo e injustiça social, como fórmula mágica para se alcançar 0 sucesso. Essa ideologia fundada no neoliberalismo ganha a legitimação de quem era o maior ídolo nacional, na época, com os três títulos mundiais conquistados em sua modalidade esportiva, reconhecida pela sua alta competitividade e por sua audiência global.

Figura 1: cena do comercial "Chegue lá - Senna”, da Nike, de 2014

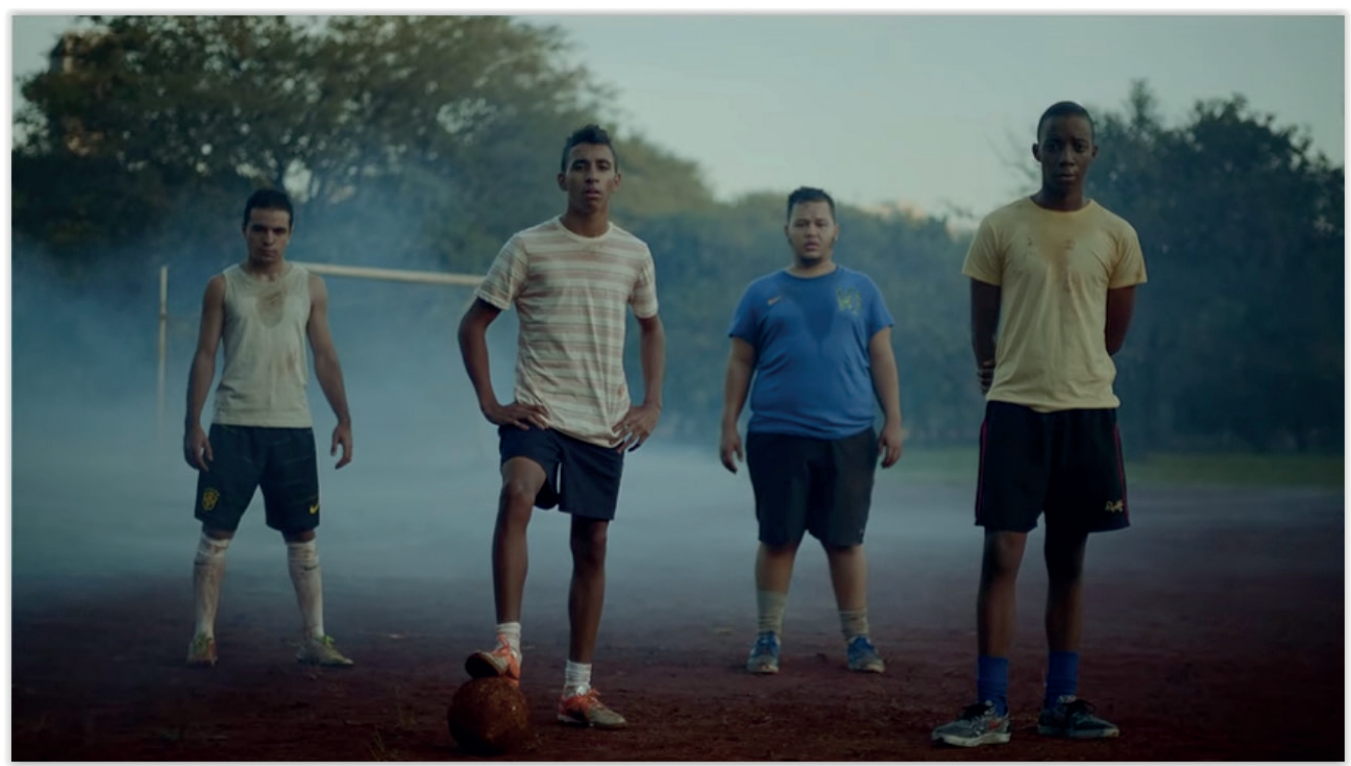

Fonte: Canal da Nike Sportswear Brasil no Youtube.

Disponível em: < https://www.youtube.com/watch?v=N02h0rmx4v0> . Acesso em: 6 mar. 2017.

Esse artigo é versão revista e ampliada de trabalho apresentado no $5^{\circ}$. COMUNICON - Congresso Internacional em Comunicação e Consumo, organizado pelo PPGCOM ESPM nos dias 5 a 7/10/2015, permanecendo inédito em publicações desde sua versão inicial.

2 Frases extraídas de entrevista feita em 1990 por João Dória Junior para o Programa Sucesso, da TV Bandeirantes, na casa do piloto em Angra dos Reis. 0 trecho citado está disponível em: https://www.youtube.com/watch?v=pcNz4l_uCTg. Acesso em: 6 mar. 2017. 
Há algo de espiritual na composição do filme em questão, no sentido atribuído por Barthes (1987), em sua noção de mitologia a partir da cultura imagética de nosso tempo. Os jovens, prostrados, vistos em slow motion, parecem estar entre 0 hipnotismo mediante a voz fantasmagórica do ídolo morto; a incorporação da inspiração para potencializar a sua performance; e a demonstração da força gerada por essa inspiração, contida nas expressões desafiadoras. Ao mesmo tempo em que representa 0 efeito das palavras nos jovens esportistas em cena, o olhar de todos eles, direcionado de forma incisiva ao espectador, é uma convocação à mobilização, à motivação de qualquer brasileiro, esteja vinculado à prática esportiva ou não. Como herança de um herói olimpiano (MORIN, 2007) para alimentar 0 imaginário de nação (não à toa, o slogan da campanha é: "Ouse ser brasileiro"), o "exemplo" de Ayrton Senna, tornado narrativa publicitária, serve a uma lógica de vinculação no mundo, de leitura da realidade brasileira, de visão transcendente de si, observada a partir da mobilização do "eu interior" para se atingir o sucesso, em "qualquer posição que você tenha na vida".

Em alinhamento com o que pode ser percebido no comercial da Nike de 2014, neste trabalho, trazemos os apontamentos de um campo de pesquisa em desenvolvimento, relativo ao que denominamos "cultura da inspiração". A abordagem metodológica na qual se baseia esta pesquisa são os estudos do discurso, a partir dos quais relacionamos os textos da cultura e sua produção simbólica com os contextos que lhes atribuem sentido. Derivada de nossos estudos recentes sobre os processos comunicacionais da cultura empreendedora e, mais especificamente, sobre 0 tema do empreendedorismo social (que desenvolvemos a partir de 2013), a proposta de estudo se funda na observação, realizada nesse período de pesquisa, da profusão de narrativas inspiracionais no cenário contemporâneo, muitas delas associadas ao espírito empreendedor que se tornou paradigmático em nosso tempo, como apontam autores como Boltanski e Chiapello (2009) e Ehrenberg (2010).

\section{Cultura e Inspiração: Questões Conceituais}

Diante da pluralidade de definições do termo cultura (como aponta WILLIAMS, 1992), selecionamos um sentido estritamente relacionado com as práticas comunicacionais, de acordo com Eagleton (2005, p. 59).

Uma expressão como "cultura dos cafés" significa não só que as pessoas frequentam cafés, mas que algumas pessoas os frequentam como um modo de vida, o que presumivelmente não fazem quando se trata de seus dentistas. Pessoas que pertencem ao mesmo lugar, profissão ou geração nem por isso constituem uma cultura; elas o fazem somente quando começam a compartilhar modos de falar, saber comum, modos de proceder, sistemas de valor, uma auto-imagem coletiva.

Nesse espectro, discutimos a possibilidade de compreensão da existência de uma cultura da 
inspiração, como algo relacionado a um modo de falar comum, às práticas narrativas que correspondem as institucionalidades, a lugares de fala consolidados e legitimados, a um sistema de valores. Trata-se de modos de narrar que, por mais que mobilizem formas ancestrais de oralidade em alguns casos, correspondem a um cenário contemporâneo de midiatização da experiência humana em função de um projeto comunicacional, que envolve a produção, circulação e consumo de narrativas.

A instrumentalização das narrativas para "inspirar" constitui um mercado de ideias (ANGENOT, 2010). A vinculação entre essa produção comunicacional e 0 empreendedorismo, em sentido amplo, aponta para certa recorrência de formas de articular a experiência humana com um "espírito", com uma visão de mundo, que, em última instância, promove, direta ou indiretamente, a ideia de uma comunidade de práticas e afetos comuns. A cultura da autoajuda, como discutida por Illouz (2011), abordada em perspectiva histórica, envolve a passagem dos processos que levam 0 espírito do ser moderno, calcado nos anseios por transformação e autotransformação, ao mercado instituído em torno das narrativas que servem de apoio psicológico. Nesse contexto, os enunciadores tidos como "inspiradores" funcionam como sistemas especialistas (GIDDENS, 2002), pautados pelo objetivo de corresponder aos anseios de uma sociedade ávida por referências, por modelos, por exemplos e histórias "inspiradores" para seguir adiante na batalha cotidiana. Esse objetivo, obviamente, passa muitas vezes pelo cálculo da produtividade mercadológica dessas mensagens, em que 0 interlocutor seria instaurado como consumidor.

Em seu trabalho de revisão conceitual do termo "inspiração", Thrash e Elliot (2003) indicam a multiplicidade de vertentes que a ele se associam. Campos de conhecimento distintos, como a religião, a arte e a psicologia apresentam significados que, vistos em conjunto, ajudam a perceber a curiosa combinação de elementos pertencentes a essa cultura da inspiração contemporânea.

A primeira vertente apresentada pelos autores articula a inspiração às "fontes sobrenaturais", em que o indivíduo é movido pela influência transcendente, como é a alegoria do papel da Musa para os poetas, que remonta à Grécia Antiga. Essa tradição é atualizada, na modernidade, para a noção de criatividade mobilizada por forças "sobrenaturais, transcendentes ou desconhecidas" (THRASH; ELLIOT, 2003, p. 871), que favorece artistas, cientistas e outros sujeitos capazes de traduzir essa influência em sua produção, comunicando e dando forma ao divino, ao transcendente. No mesmo espectro, os autores incluem a tradição judaico-cristã, em que 0 termo revelação se refere à difusão do conhecimento divino para 0 indivíduo, enquanto o termo inspiração é reservado ao ato de transmitir ou traduzir a revelação para a forma escrita, para ser 
disseminada entre os seres humanos. A imagem bíblica do profeta Moisés (Fig. 2), recebendo de Deus a revelação dos Dez Mandamentos, que por sua vez é transmitida para as sagradas tábuas de pedra, demonstra esse processo de revelação e inspiração para caracterizar a mensagem divina mediada pelo humano.

Figura 2: 0 s Dez Mandamentos, por Spagnoletto, 1638

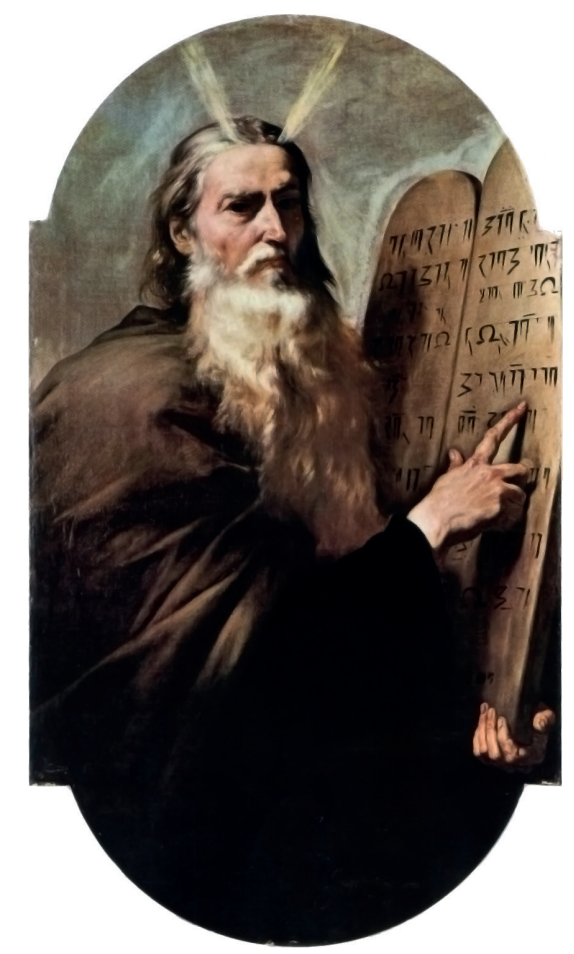

Fonte: Wikipedia.

Disponível em: <https://pt.wikipedia.org/wiki/Dez Mandamentos\#/media/File:Moses041.jpg>. Acesso em: 6 mar. 2017.

A segunda vertente é a inspiração por "fontes intrapsíquicas" (THRASH; ELLIOT, 2003, p. 872), originada, obviamente, com a emergência do campo de conhecimentos da psicologia, no final do século XIX. Nesse contexto, a influência divina é reposicionada como iluminação criativa (o chamado "insight"), descrita como um processo psíquico de quatro fases: preparação, incubação, iluminação e verificação. Enquanto as etapas de preparação e verificação são dominadas pela consciência, a incubação e a iluminação são do domínio do inconsciente. Outra vertente psicológica vai se apoiar nas teorias freudianas para descrever a inspiração criativa como regressão a um estágio primário do ego, identificado com a infância, em que o pensamento flexível favoreceria a geração de novas ideias.

Em termos gerais, essa vertente, para os autores, indica algumas recorrências em meio à diversidade: entre elas, destacamos o papel da motivação, uma vez que as ideias e iluminações são situadas como desencadeadoras da ação criativa. Enfim, a inspiração, nesse sentido, é conceituada como um "estado motivacional" (THRASH; ELLIOT, 2003, p. 872) que está diretamente relacionado com uma dimensão pragmática, resultante do desencadeamento do ato produtivo, seja do artista, do cientista, do indivíduo inovador.

A terceira vertente trata da inspiração a partir de "fatores ambientais", ou seja, de elementos externos - que, como os autores mesmo apontam, remontam à tradição anteriormente discutida das fontes sobrenaturais da inspiração. No entanto, diferencia-se da primeira vertente ao instrumentalizar a inspiração, incorporando as contribuições da psicologia positiva apontadas na segunda vertente. Nesse aspecto, a exposição a modelos de sucesso do outro, a "histórias de 
vida exemplares" (BUONANNO, 2011), despertaria

a busca por um "Eu futuro" melhor ${ }^{3}$ (p. 873, tradução nossa), de uma versão "superior" de si próprio, que seria resultante de um processo de autotransformação. Essa vertente trata do papel da emoção positiva que mobiliza as "emoções auto transcendentes"4 (p. 872, tradução nossa), ou a "auto transcendência" baseada na incorporação de valores, de qualidades humanas presentes no modelo, que serve de referência numa perspectiva de comparação social. 0 exemplo discutido por Thrash e Elliot relativo a essa vertente é uma pesquisa de audiência, que concluiu que a exposição a um filme sobre Madre Teresa de Calcutá produziu uma resposta "positiva" em seus espectadores.

Por fim, como síntese da revisão da literatura e unificação das características elencadas em sua proposta conceitual, Thrash e Elliot (2003, p. 873) indicam que a

Inspiração é evocada por alguns estímulos desencadeadores - seja uma revelação divina, uma iluminação criativa, ou uma pessoa ou objeto presente no ambiente externo. 0 indivíduo inspirado é mobilizado pela verdade, ingenuidade, bondade, beleza, ou superioridade do objeto do estímulo externo - sendo motivado a transmitir, atualizar, ou emular as qualidades transcendentes que 0 inspiraram. Inspiração é assim conceituada como um amplo construto que se estende por múltiplos domínios de conhecimento (por exemplo, religioso, criativo), diversas fontes (intrapsíquica, externa), desencadeadores distintos (iluminação, natureza), qualidades transcendentes (beleza, bondade), sendo aplicada a objetivos diferentes (produtos, identidades possíveis) (tradução nossa).

Com base no levantamento conceitual e das características do termo inspiração feitos por Thrash e Elliot, podemos concluir que os processos comunicacionais são inerentes a esses fenômenos apresentados, principalmente na terceira vertenteonde encontramos a sua dimensão midiática. Nesse espectro, em que a ideologia do empreendedorismo é disseminada a partir de produtos "inspiracionais" dos mais diversos - de palestras veiculadas pela internet a blogs de autoajuda, de empreendimentos sociais a propostas educacionais, entre outras possibilidades de consumo dessa cultura - é que localizamos o nosso objeto de estudo.

\section{A cultura da inspiração como objeto de estudo}

Durante o desenvolvimento de trabalhos anteriores (ver CASAQUI, 2015), identificamos

Tradução livre da expressão "better future self".

"Self-transcendent emotions", no original.

"Inspiration is evoked by some trigger stimulus, be it a divine revelation, a creative illumination, or a person or object in the external environment. The inspired individual is moved by the truth, ingenuity, goodness, beauty, or superiority of the trigger object and is motivated to transmit, actualize, or emulate those transcendent qualities. Inspiration is thus conceptualized as a broad construct that spans multiple content domains (e.g., religious, creative), sources (e.g., intrapsychic, external), triggers (e.g., illumination, nature), transcendent qualities (e.g., beauty, goodness), and targets (e.g., products, possible selves)". 
a inspiração como proposta de transformação social, no espectro do empreendedorismo social. Como aparece nitidamente na apresentação do Projeto Imagina na Copa, cujo objeto era a produção de 75 vídeos inspiracionais, com 0 objetivo de promover modelos, originados de iniciativas de jovens - 0 que guarda relação intrínseca com o imaginário da Geração Y, em chave positiva:

Toda semana você pode assistir aqui no site às histórias de jovens que já estão mudando o país para melhor. Você pode se inspirar e ver que é possível promover impacto em diversas causas sociais, seja por meio de trabalho voluntário, seja por ações pontuais, projetos e negócios em prol da sociedade. ${ }^{6}$

0 Imagina na Copa é um projeto "inspirado" no painel elaborado pela pesquisa Sonho Brasileiro (PROJETO SONHO BRASILEIRO, 2011), realizada pela agência Box18247, que elege os jovens na faixa dos 18 a 24 anos como o "centro primário de influência" da transformação da sociedade brasileira. Nas palavras contidas no relatório da pesquisa, podemos ver a controversa tese: "Seu estilo de vida [do jovem de 18-24 anos] acaba impactando os mais velhos e os mais jovens: enquanto os mais jovens aspiram ser como eles, os mais velhos se inspiram em seus valores e comportamentos" (PROJETO SONHO BRASILEIR0, 2011, p. 84). Ainda nas palavras do relatório da Box, encontramos a afirmação de que "os jovens de 18 a 24 anos [são] uma poderosa 'antena' para se captar o espírito de um determinado tempo" (p. 85). Ao edificar a tese de que os jovens brasileiros dessa geração são a fonte da inspiração, nos termos de uma geração "sonhadora", "transformadora", "empreendedora" e comprometida com o bem comum, a Box1824 constrói a imagem do jovem como um ser transcendente, em alusão à vertente da inspiração baseada nas "fontes sobrenaturais". Mais do que algo baseado concretamente em pesquisas, percebemos que há algo de mítico e "engajado" na leitura do material empírico levantado pela agência, voltada a identificar tendências de comportamento e de consumo.

0 projeto de mobilização social Imagina na Copa é baseado em uma cadeia de produção, circulação e consumo de mensagens, ou histórias de vida exemplares, marcadas na prática empreendedora associada ao bem comum. Encerrado o projeto como previsto, no início da Copa do Mundo de futebol de 2014, a mesma equipe concebe 0 projeto Imagina.vc, que obteve financiamento coletivo através da plataforma de crowdfunding Catarse $^{8}$, atingindo o capital total de $\mathrm{R} \$ 61.147,00$, superior à meta de $\mathrm{R} \$ 56.000,00$ estipulada para realização do projeto. 0 novo projeto é definido da seguinte forma: "0 Imagina.vc é uma

Fonte: http://imaginanacopa.com.br/sobre/. Acesso em: 7 mar. 2017.

Site da agência: www.box1824.com.br.

Página do projeto na plataforma Catarse disponível em: https://www.catarse.me/imaginavc. Acesso em: 7 mar. 2017. 
provocação para mais pessoas fazerem mais coisas em mais lugares". Mediante a mobilização de temas e produção de "conteúdos", difundidos em vídeos, infográficos, debates, o projeto assume novamente 0 papel de inspirar, implicitamente colocado a partir da noção de motivar à ação. Seu modus operandi (Fig. 3), ou seja, o modelo comunicacional que pauta suas operações, é sintetizado pelas atividades de
Curadoria ("Buscamos e encontramos pessoas e projetos que são referência nos diferentes temas sociais"); Articulação ("Acionamos especialistas nos temas e produtores de conteúdo para contribuir com diferentes visões"); e Produção ("Produzimos variados tipos de conteúdos: vídeos, infográficos, oficinas, fotos, etc. para inspirar mais pessoas provocando transformações").

Figura 3: Apresentação gráfica do funcionamento do Projeto Imagina.vc

COMO FUNCIONA O IMAGINA.VC?

Somos uma plataforma de conteúdo online de impacto social.
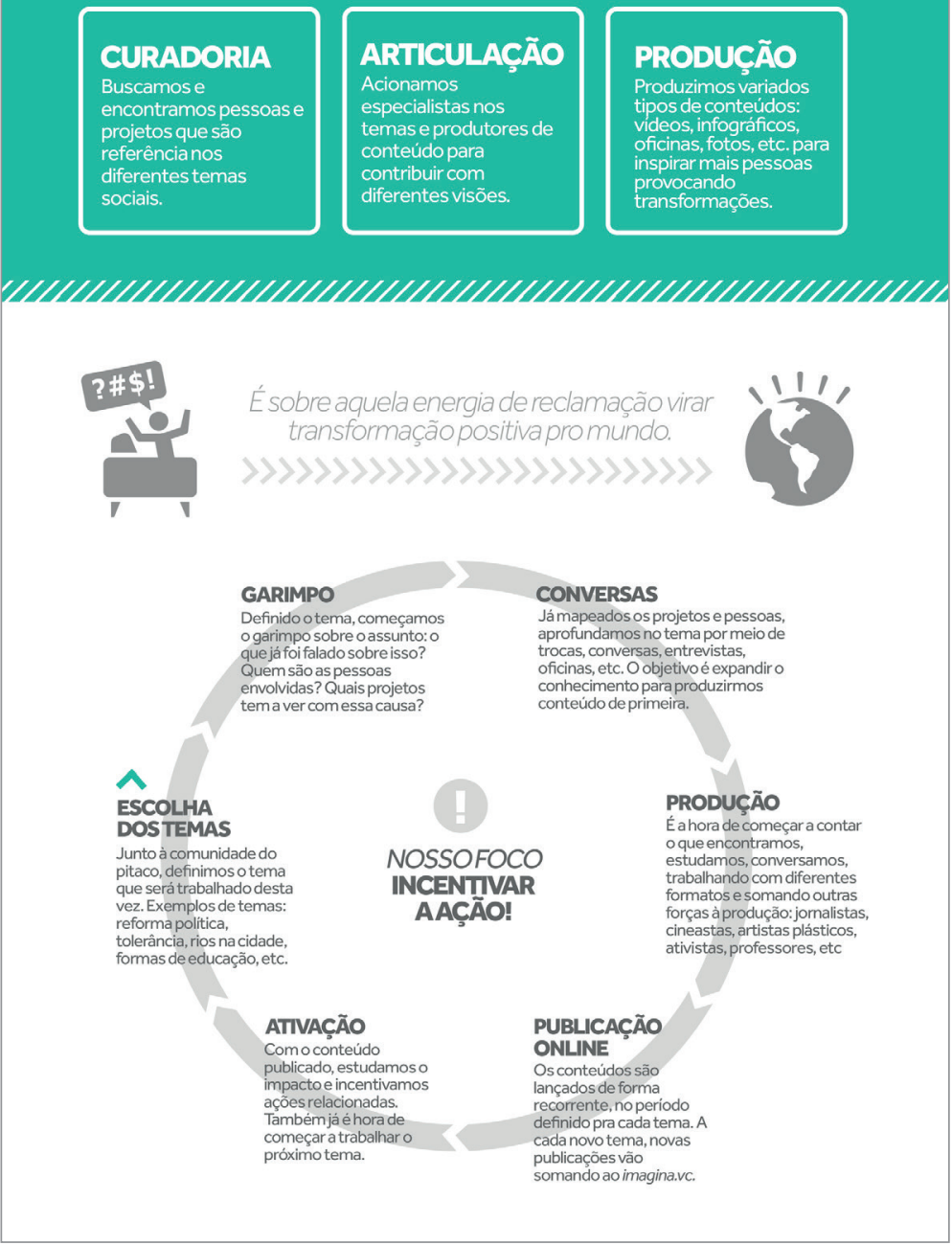

Fonte: < https://www.catarse.me/imaginavc>. Acesso em: 7 mar. 2017. 
Na breve apresentação dos dois projetos citados, identificamos o campo semântico da inspiração incorporado a um projeto de sociedade. 0 ideário da sociedade empreendedora defendido pela obra do teórico do marketing Peter Drucker (2011) se concretiza, na atribuição do bem comum a ser capitaneado por líderes empreendedores, por seus projetos inspiradores e pelos seguidores dos "bons exemplos". Dessa forma, a inspiração originada de um fator externo se apresenta: o outro que é bem sucedido em um projeto é alçado ao status de modelo de cultura, legitimado pela visibilidade promovida pelos vídeos do projeto Imagina na Copa. Os "fatores ambientais", no entanto, combinam-se a um projeto de autotransformação, ou seja, de "fatores intrapsíquicos", quando consideramos especialmente 0 conteúdo do Imagina.vc com seu objetivo de incentivar o insight, a prática da ação concretizada em projetos, em atitude empreendedora, que parte de uma transformação de si. Nesse sentido, o conteúdo promovido pelo projeto guarda relação com o mercado da autoajuda. Sua associação com as narrativas terapêuticas discutidas por Illouz (2011) torna-se inevitável: a "transformação positiva do mundo" parte do alinhamento do self a uma inspiração compreendida como inovação, identificada com o imaginário da sociedade empreendedora. 0 "Eu futuro melhor" (THRASH; ELLIOT, 2003, p. 873) é articulado como projeto motivacional de sociedade, em que uma coletividade de egos empreendedores, autotransformados, promoveria a transformação da sociedade brasileira, tendo como pano de fundo a psicologia positiva aplicada aos planos de negócios, agora tidos como parte indissociável dos projetos sociais, pela via do empreendedorismo social.

Nesse contexto em que as histórias de vida podem ser reconhecidas como "inspiradoras", a narrativização da própria vida em chave motivacional, com vistas a servir de modelo à trajetória do outro, ganha espaço crescente no espectro da inspiração como cultura. Ao mesmo tempo em que se poderia reconhecer um processo de "autotranscendência", há certa banalização da noção do divino, caso consideremos que, entre as vidas mais exemplares de todos os tempos, está a de Jesus Cristo, inclusive citada por alguns empreendedores sociais, entrevistados durante a nossa pesquisa, como fonte principal de inspiração.

Como defende Rose (2001, p. 33), "0 ser humano não é a base eterna da história e da cultura humanas, mas um artefato histórico e cultural". 0 autor propõe a abordagem da genealogia $d a$ subjetivação, na qual seu maior interesse está centrado nas "práticas pelas quais as pessoas são compreendidas e pelas quais se age sobre elas" (p. 34). Dessa forma, o empreendedorismo pode ser entendido como uma técnica de si, pois ultrapassa a prática laboral para se firmar 
como um paradigma comportamental, moral, como uma lente a partir da qual a narrativa de vida se articula.

0 grande paradigma da cultura da inspiração, nesse sentido da produção de si como narrativa inspiracional, são as apresentações denominadas TED Talks (Fig. 4). TED é uma abreviatura de "Technology, Entertainment and Design" (Tecnologia, Entretenimento e Design), cuja convergência dos termos, segundo a instituição, cobriria quase a totalidade dos temas tratados em suas palestras, ao menos em suas origens - uma vez que a amplitude quase ilimitada de temas é a característica atual do evento. Trata-se de uma organização global sem fins lucrativos fundada em 1984, cuja atividade é a promoção das conferências com o objetivo de "difundir ideias, usualmente no formato de curtas e poderosas falas (em 18 minutos ou menos)"10.

Figura 4: Imagem de uma palestra do evento TED Talks

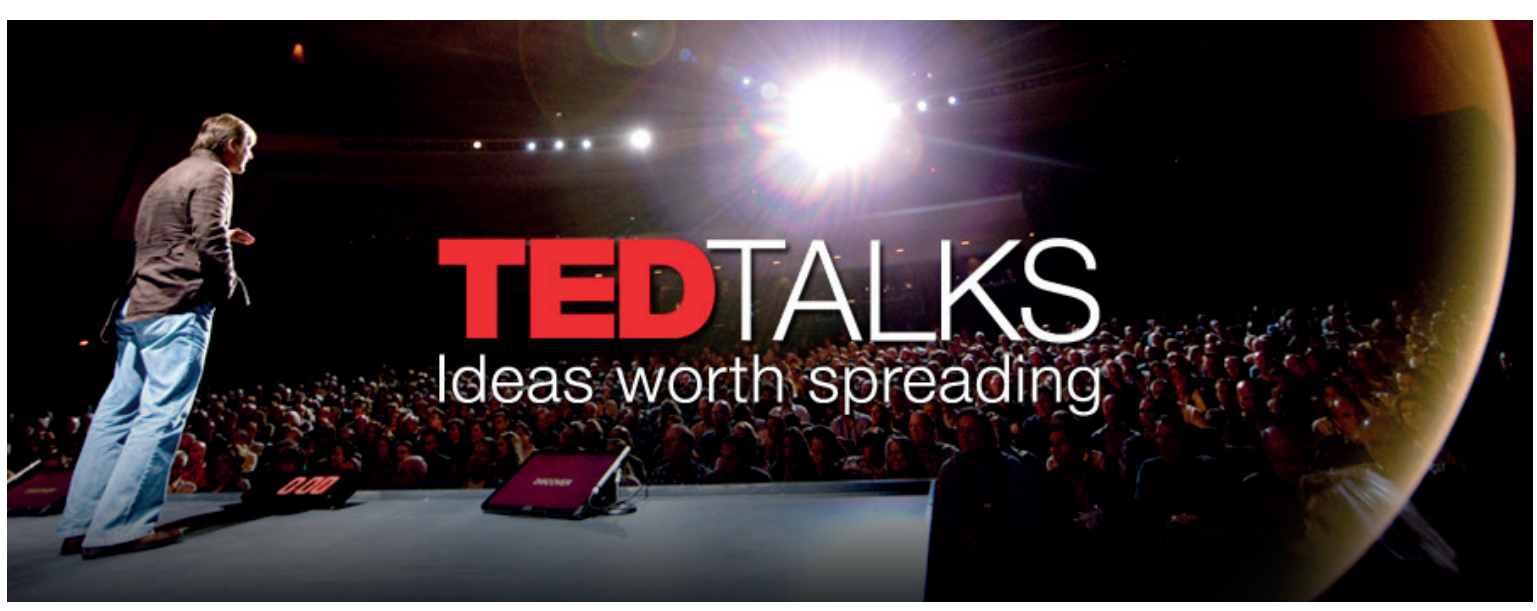

Fonte: < http://www.kevaplanks.com/ted-talks-and-keva/>. Acesso em: 7 mar. 2017.

Essas conferências, gravadas e tornadas

disponíveis no site da instituição em mais de 100 línguas, já foram vistas e compartilhadas por milhões de espectadores nas redes sociais. Seu slogan, "ideas worth spreading" ("ideias que merecem ser espalhadas"), dá o tom de uma cultura seletiva, em que a mensagem valorosa é aquela capaz de convencer, de emocionar, de promover "transformações" na vida das pessoas, mesmo que sintetizadas em 18 minutos no máximo, em uma forma de espiritualidade incorporada à oralidade midiatizada. A disseminação dessa mensagem traz a conotação da "boa nova", da revelação transmitida pelo 
testemunho potente, pelo poder de narrar desses novos pastores - os palestrantes e sua capacidade de produção de afetos em larga escala, em sintonia com o "espírito TED", de convergência transcendente entre os oradores e seu auditório.

0 evento globalizado se desdobra em edições regionais organizadas de forma "independente" por comunidades locais - os chamados TEDx Talks -, que acontecem, entre outros lugares, na cidade de São Paulo, Brasil. Entre os destaques de eventos recentes realizados no país estão os criadores dos já comentados Projetos Imagina na Copa e Imagina.vc, como a palestra de Fernanda Cabral no TEDx São Paulo de maio de $2015^{11}$. A trajetória de vida e, especialmente, a experiência na realização dos projetos bem sucedidos, articuladas à cena empreendedora social, são transformadas em percurso narrativo com formato delimitado, e com certas características recorrentes para ter eficácia no objetivo de "falar, convencer, emocionar", como revela o título do livro de Carmine Gallo (GALLO, 2014) - um manual para a preparação de uma palestra impactante e, principalmente, "inspiradora". A autora oferece números que permitem identificar o TED como fenômeno em escala global e espraiado em nossa cultura recente:
Em 13 de novembro de 2012, as apresentações do TED.com bateram a marca de um bilhão de visualizações e atualmente são vistas em média 1,5 bilhão de vezes por dia (GALL0, 2014, p. 12, grifos do autor).

À parte da aura descompromissada de compartilhamento de ideias, exemplos inspiradores, narrativas sedutoras e envolventes com vistas ao bem comum, revelase, no manual, o potencial econômico desse universo que remete à ágora grega, porém em contexto mercadológico, midiático, globalizado:

0 TED.com é uma verdadeira mina de ouro para aqueles que ambicionam dominar as áreas de comunicação, persuasão e oratória. A obra apresentará as ferramentas necessárias e vai ensinar você a usá-las para encontrar a sua própria voz e talvez até 0 seu destino (GALLO, 2014, p. 20).

\section{Cultura Empreendedora, Nova Era e Inspiração}

\begin{abstract}
A cultura empreendedora de nosso tempo tem nuances que instigam a pensar sobre a questão da inspiração. Como no caso de The Happy Startup School ${ }^{12}$, uma escola de empreendedorismo sui generis, pois prega a equação lucro + propósito $=$ felicidade. Em seu discurso, profundamente marcado nas imagens visuais, há algo de transcendente - que escapa do divino, marcado na religiosidade tradicional, para se tornar a
\end{abstract}


iluminação da "autotranscendência" pela via do empreendedorismo "feliz". Essa abordagem ecoa a noção de felicidade como imperativo de nosso tempo (FREIRE FILHO, 2010). Como estado de espírito articulado diretamente com o trabalho, mais especificamente com a ação empreendedora, a proposta da Happy Startup School remete à ideia de que a felicidade pode ser produzida por essa técnica, pela competência arraigada na forma como 0 capitalismo opera. Identificamos que esse discurso amalgama elementos religiosos, espirituais, motivacionais e pragmáticos também, uma vez que tratamos da atividade que guarda relação intrínseca com o sistema capitalista e seu compromisso com a produção do lucro. Num capitalismo que alia a sua retórica à chamada "Nova Era", o fundador de um empreendimento deve "parar de fazer negócios e começar a ser humano" (Fig. 5).

Figura 5: ilustração de um dos artigos do site The Happy Start School

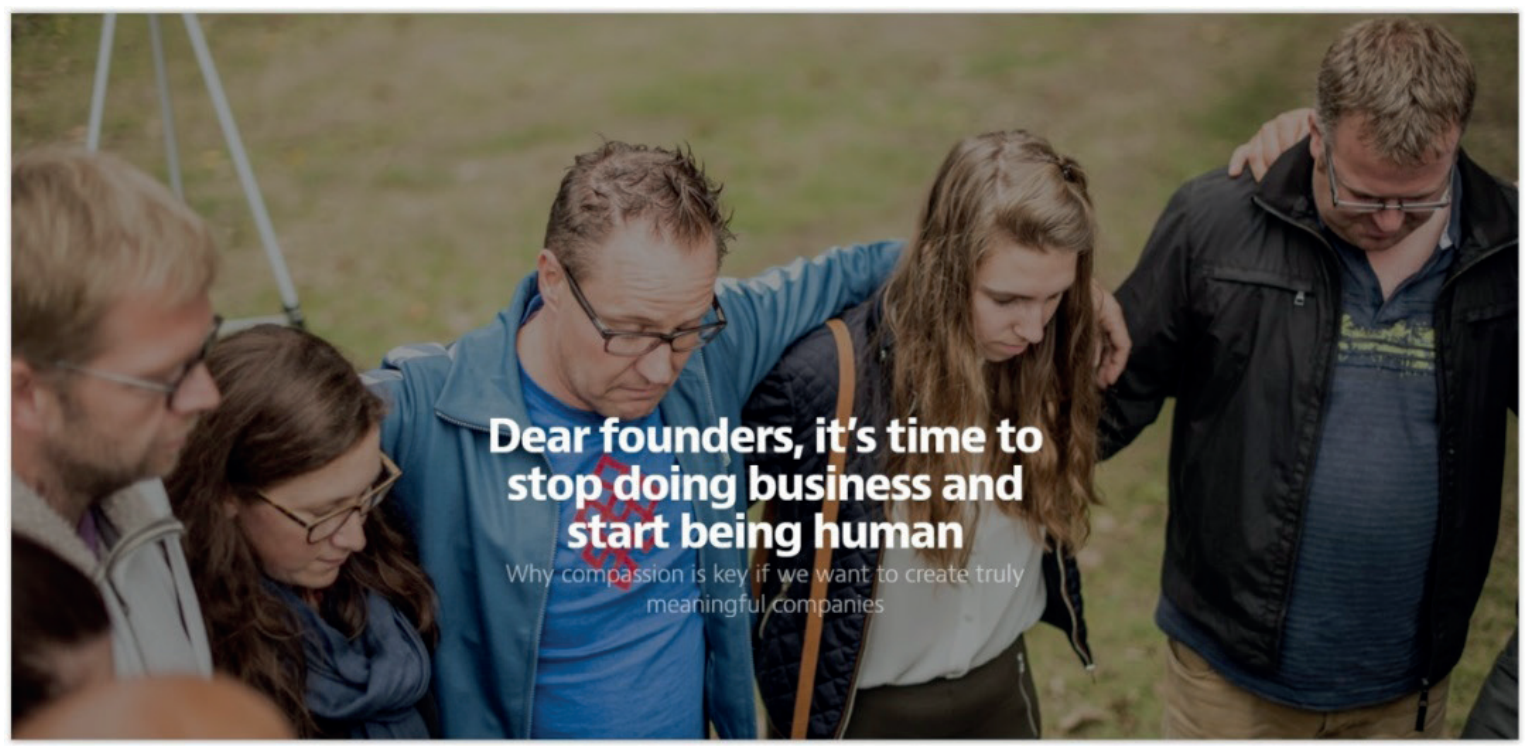

Fonte: Site da instituição. Acesso em: 6 mar. 2017.

0 método educacional é baseado fortemente no uso de palestras, ou de "falas inspiradoras", em eventos como o Happy Start Summercamp (Fig. 6), um acampamento de três dias com palestras "inspiradoras", "oficinas campestres", atividades diversas em contato com a natureza e a vida do campo, que estimulam a troca coletiva e o sentimento de comunidade entre os cerca de 100 participantes, identificados como "pessoas inspiradoras" - tudo para "ajudá-lo a fazer a transformação acontecer". 
Figura 6: imagem do evento Happy Startup Summercamp

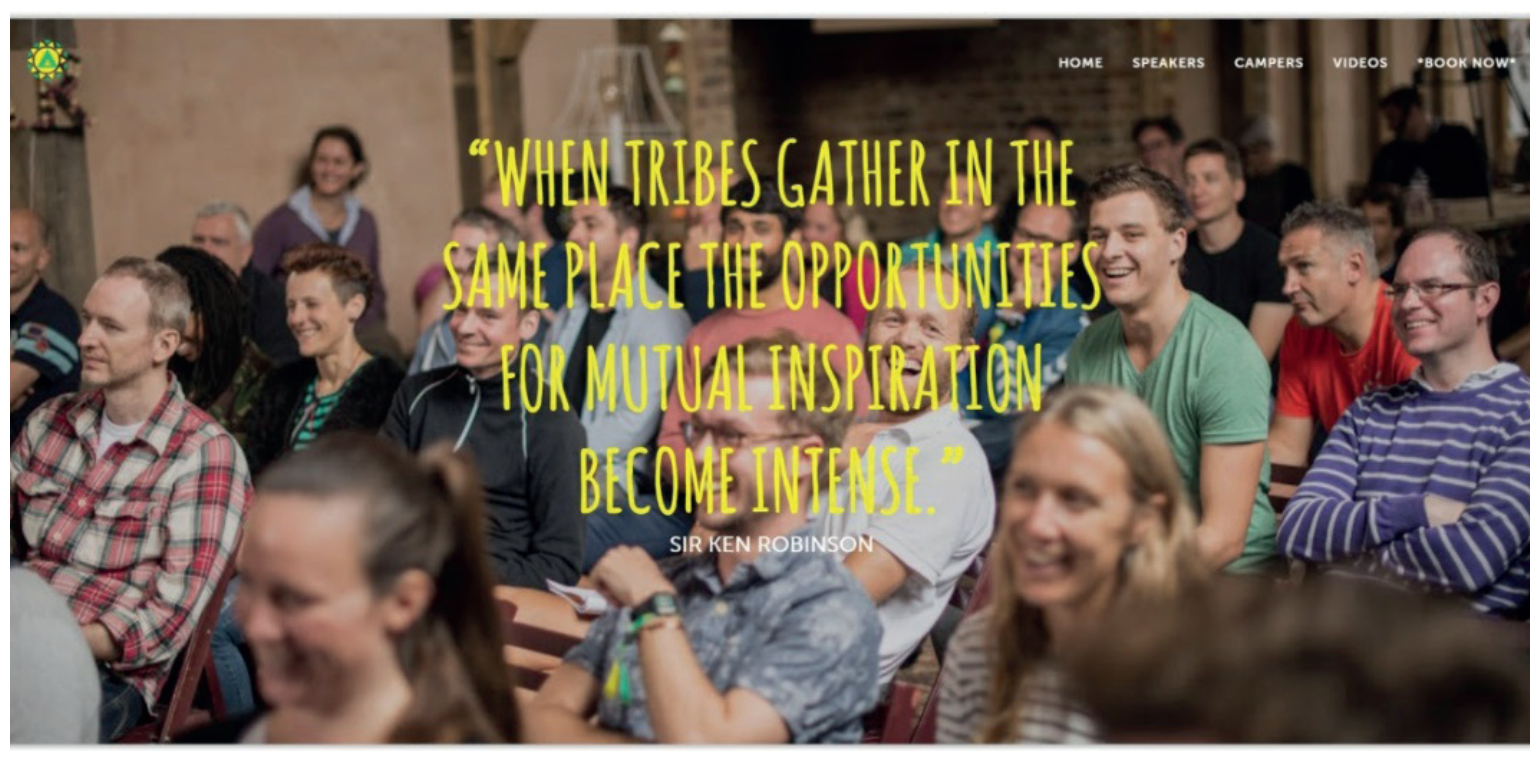

Fonte: Site do evento.

Disponível em: http://www.happystartupsummer.camp/. Acesso em: 6 mar. 2017.

No Brasil, um dos exemplos dessa cultura é

o Impact Hub São Paulo, partícula regional

de uma comunidade global de fomento ao

empreendedorismo e à inovação, "um dos 60

Impact Hubs espalhados pelo mundo". Em sua

autodefinição, "o Impact Hub São Paulo é 0

seu primeiro passo para se conectar com uma

comunidade global de mais de 7.000 pessoas

incríveis e inspiradoras":

\section{QUE É 0 IMPACT HUB SÃO PAULO?}

Nós acreditamos que um mundo melhor é criado através de realizações conjuntas de indivíduos criativos, comprometidos, apaixonados e focados em um propósito comum.

Uma rede global de empreendedores de impacto. Um espaço de trabalho compartilhado. Um laboratório de inovação. Uma incubadora de empresas. Um centro colaborativo de empreendedores sociais. Nós oferecemos um ecossistema único de recursos, inspiração e oportunidades de colaboração para aumentar o seu impacto. Nossa comunidade diversificada irá inspirar, conectar e permitir-lhe desenvolver o seu melhor trabalho em cada passo do caminho. ${ }^{13}$

No discurso do Impact Hub, fica evidente

a conexão entre o perfil comportamental, a

prática do empreendedorismo e 0 ambiente que

favorece uma sensibilidade moldada à inovação,

à criatividade, a serviço do sistema produtivo

capitalista. A partir dos casos citados, observamos

os deslizamentos de sentido na construção

da atividade empreendedora rearticulada em

função da cultura da autoajuda, como estuda 
Rüdiger (1996) e, mais especificamente, com 0 imaginário da Nova Era, também discutido por Campanella e Castellano (2015). 0s casos do Happy Startup Summercamp e do Impact Hub São Paulo ilustram bem o ideário que constitui a religiosidade do self: "os praticantes da Nova Era defendem a recuperação da relação primordial entre homem e natureza e o comprometimento com uma série de dispositivos relativos a um 'eu divino' existente em cada indivíduo" (CAMPANELLA; CASTELLANO, 2015, p. 176). Essa religiosidade do self é traduzida de forma pragmática, utilitária, em que essa "divindade interior" pode revelar uma espécie de espírito empreendedor, sagrado e transcendente, munido de missão, de propósito, de sonhos acompanhados da capacitação técnica para efetivar esses elementos sobrenaturais em modelos de negócios, em cultura corporativa, em lucro sacralizado. A imagem da felicidade é a representação do sucesso sem culpa, do espírito do capitalismo "com propósito", que atualiza a ética protestante (WEBER, 2004) da era moderna para 0 universo do mundo conexionista tratado por Boltanski e Chiapello (2009), no qual as relações pessoais são vistas como produtivas, como passíveis de mercantilização. Se 0 empreendedorismo se faz religião, a comunhão entre seus seguidores pode também ser chamada de networking.

\section{Considerações finais}

Nos exemplos acima, e também no quadro mais amplo dos casos apresentados, temos a concretização da ideia de que o empreendedorismo se transformou na panaceia, na cura dos males de nosso tempo: do desemprego à infelicidade, passando pela crise de valores, tudo é passível de solução, mediante a prática da atividade empreendedora que combina plano de negócios, psicologia positiva, inspiração. Nesse sentido, basicamente temos a mobilização das diversas fontes da inspiração: 0 empreendedorismo ganha um caráter sobrenatural, bem como aqueles indivíduos eleitos como exemplos de sucesso para essa cultura. Em outra vertente, as fontes intrapsíquicas são estimuladas por fatores externos, pelos exemplos inspiradores e pelo ambiente todo voltado para essa prática, para que os indivíduos possam encontrar sua força interior, para empreenderem a si mesmos como seres produtivos, empregados (ou "autoempregados", capazes de gerar suas próprias empresas), felizes, ativos e com valores sólidos e positivos, comprometidos com a coletividade. Mercado de autoajuda, cultura terapêutica, Nova Era, religiosidade do self: tudo isso se combina numa cultura empreendedora que alimenta as lógicas de justificação do sistema capitalista (BOLTANSKI; CHIAPELLO, 2009) e, em consequência, promove 0 engajamento de jovens pelo mundo todo.

Como apontamos, por meio da reflexão sobre os fenômenos apresentados neste trabalho, tratamos de um campo de estudos que ultrapassa a especificidade da noção de inspiração, principalmente quando articulada à cultura 
empreendedora. Estamos diante de um projeto de sociedade que universaliza o ideário da sociedade empreendedora para todos, projetando um futuro totalizante, baseado na monocultura que abarca e traduz toda a história, a produção de conhecimento, a atividade humana e as questões psíquicas, comunitárias, de realização pessoal ou de sucesso da nação. Os processos comunicacionais que difundem essa cultura são essenciais no projeto da sociedade empreendedora e seus enquadramentos, suas formas de convocação, suas propostas de engajamento dos indivíduos.

\section{Referências}

ANGENOT, Marc. El discurso social: Los limites históricos de lo pensable y lo decible. Buenos Aires: Siglo XXI, 2010.

BARTHES, Roland. Mitologias. São Paulo: Difel, 1987. BOLTANSKI, Luc; CHIAPELLO, Ève. 0 novo espírito do capitalismo. São Paulo: Martins Fontes, 2009. BUONANNO, Milly. Histórias de vida exemplares. Biografias. MATRIZes, ano 5, n.1, p. 63-84, 2011.

CAMPANELLA, Bruno e CASTELLANO, Mayka. Cultura terapêutica e Nova Era: comunicando a "religiosidade do self". Comunicação, Mídia e Consumo, São Paulo, v. 12, n. 33, p. 1-30, jan./abr. 2015.

CASAQUI, Vander. A invenção de um país de empreendedores sociais: "Imagina na Copa" e seu projeto de Brasil. E-Compós, vol. 18, no. 1, p. 1-17, jan./ abr. 2015. Disponível em: < http://www.compos.org. br/seer/index.php/e-compos/article/view/1104/810>. Acesso em: 3 mar. 2017.

\section{DRUCKER, Peter F. Inovação e espírito} empreendedor: prática e princípios. São Paulo: Cengage Learning, 2011.
EAGLETON, Terry. A ideia de cultura. São Paulo: Ed. Unesp, 2005.

EHRENBERG, Alain. 0 culto da performance: da aventura empreendedora à depressão nervosa. Aparecida - SP: Idéias \& Letras, 2010.

FREIRE FILHO, João. (Org.) Ser feliz hoje: reflexões sobre o imperativo da felicidade. Rio de Janeiro: Ed. FGV, 2010.

GALLO, Carmine. TED: falar, convencer, emocionar: como se apresentar para grandes plateias. São Paulo: Saraiva, 2014.

GIDDENS, Anthony. Modernidade e identidade. Rio de Janeiro: Zahar, 2002.

ILLOUZ, Eva. 0 amor nos tempos do capitalismo. Rio de Janeiro: Zahar, 2011.

MORIN, Edgar. Cultura de massas no século XX - Vol 1, Neurose. Rio de Janeiro: Forense Universitária, 2007. ROSE, Nikolas. Como se deve fazer a história do eu? Educação \& Realidade, $n^{0} 26$ (1), p.33-57, jan./jul. 2001.

RÜDIGER, Francisco. Literatura de autoajuda e individualismo. Porto Alegre: UFRGS, 1996.

SOUZA, Jessé. 0s batalhadores brasileiros: nova classe média ou nova classe trabalhadora? Belo Horizonte: Ed. UFMG, 2010.

THRASH, Todd M.; ELLIOT, Andrew J. Inspiration as a psychological construct. Journal of Personality and

Social Psychology, vol. 84, no. 4, p. 871-889, 2003.

WEBER, Max. A ética protestante e o "espírito" do capitalismo. São Paulo: Companhia das Letras, 2004.

WILLIAMS, Raymond. Cultura. Rio de Janeiro: Paz e Terra, 1992.

\section{Sites consultados}

AYRTON Senna inspira novo comercial da Nike.

Revista Exame, 11 jun. 2014. Disponível em: http:// 
exame.abril.com.br/marketing/noticias/ayrton-senna-

inspira-novo-comercial-da-nike. Acesso em: 6 mar. 2017.

CHEGUE LÁ - Senna. Cliente: Nike do Brasil. Produto:

Nike Futebol. São Paulo, Brasil. Ano de Produção: 2014.

Agência: Wieden+Kennedy SP. Produtora: Stink SP.

Comercial (30 seg), cor. Disponível em: < https://www.

youtube.com/watch? $=\mathrm{N} 02 \mathrm{~h} 0 \mathrm{rmx} 4 \mathrm{v} 0>$. Acesso em: 7

mar. 2017.

PROJETO Sonho Brasileiro. Pesquisa realizada pela agência Box1824, São Paulo, 2011. Disponível em: < https://pt.slideshare.net/fernandapugliero/sonhobrasileiro-box-1824> . Acesso em: 6 mar. 2017.

SUCESSO. Apresentado por João Dória Junior. São

Paulo: Rede Bandeirantes de Televisão, 1990. Duração

60 min. Entrevista com Ayrton Senna. 


\section{Critical approach to the culture of inspiration: production of narratives and the ideology of the entrepreneurial society}

\section{Abstract}

In the contemporary context, inspiration is a recurrent term, when we observe the discourses that spread the ideology of entrepreneurship. In a critical approach, our research aims to analyze the role of inspirational narratives in publicizing the ideology of the "entrepreneurial society". The object of this study includes discourses of entrepreneurs and social entrepreneurs, motivational talks, among other media products that take the mission to inspire people. The result of this mapping points to the culture of inspiration as a key element to promote the engagement of individuals in the capitalism of our time, as discussed by Boltanski and Chiapello (2009).

\section{Keywords}

Communication and consumption. Culture of inspiration. Entrepreneurial culture. Discourse.

\section{Abordaje crítico de la cultura}

\section{de la inspiración: producción}

\section{de narrativas y el ideario}

\section{de la sociedad emprendedora}

\section{Resumen}

En el contexto actual, la inspiración es un término recurrente, cuando nos fijamos en los discursos que propagan la ideología del emprendimiento. En aproximación crítica, nuestra investigación tiene como objetivo analizar el rol de las narrativas de inspiración en la difusión de las ideas de la "sociedad emprendedora". El objeto de este estudio incluye discursos de emprendedores y emprendedores sociales, charlas motivacionales, entre otros productos comunicacionales que tienen la misión de inspirar. El resultado de ese mapeo señala la cultura de la inspiración como un elemento clave para promover la participación de los sujetos en el capitalismo de nuestro tiempo, como fue discutido por Boltanski y Chiapello (2009).

\section{Palabras clave}

Comunicación y consumo. Cultura de la inspiración. cultura emprendedora. Discurso. 


\section{Expediente}

A revista E-Compós é a publicação científica em formato eletrônico da Associação Nacional dos Programas de Pós-Graduação em Comunicação (Compós). Lançada em 2004, tem como principal finalidade difundir a produção acadêmica de pesquisadores da área de Comunicação, inseridos em instituições do Brasil e do exterior.

\section{E-COMPÓS I www.e-compos.org.br I E-ISSN 1808-2599}

Revista da Associação Nacional dos Programas de Pós-Graduação em Comunicação. Brasília, v.20, n.2, maio/ago. 2017. A identificação das edições, a partir de 2008, passa a ser volume anual com três números. Indexada por Latindex I www.latindex.unam.mx

\section{CONSELHO EDITORIAL}

Alda Cristina Silva da Costa, Universidade Federal do Pará, Brasil Alfredo Luiz Paes de Oliveira Suppia, Universidade Estadual de Campinas, Brasil Álvaro Larangeira, Universidade Tuiuti do Paraná, Brasil Ana Carolina D. Escosteguy, Pontifícia Universidade Católica do Rio Grande do Sul, Brasil Ana Regina Barros Rego Leal, Universidade Federal do Piauí, Brasil Ana Carolina Rocha Pessôa Temer, Universidade Federal de Goiás, Brasil Andrea França, Pontifícia Universidade Católica do Rio de Janeiro, Brasil André Luiz Martins Lemos, Universidade Federal da Bahia, Brasil Angela Cristina Salgueiro Marques, Faculdade Cásper Líbero, Brasil Ângela Freire Prysthon, Universidade Federal de Pernambuco, Brasil Antonio Carlos Hohlfeldt, Pontifícia Universidade Católica do Rio Grande do Sul, Brasil Arthur Ituassu, Pontifícia Universidade Católica do Rio de Janeiro, Brasil Bruno Campanella, Universidade Federal Fluminense, Brasil Cláudio Novaes Pinto Coelho, Faculdade Cásper Líbero, Brasil Carlos Eduardo Franciscato, Universidade Federal de Sergipe, Brasil Denise Tavares da Silva, Universidade Federal Fluminense, Brasil Eduardo Vicente, Universidade de São Paulo, Brasil Eliza Bachega Casadei, Escola Superior de Propaganda e Marketing - SP, Brasil Elizabeth Nicolau Saad Corrêa, Universidade de São Paulo, Brasil Erick Felinto de Oliveira, Universidade do Estado do Rio de Janeiro, Brasil Erly Vieira Júnior, Universidade Federal do Espírito Santo, Brasil Francisco de Assis, FIAM-FAAM Centro Universitário, Brasil Francisco Elinaldo Teixeira, Universidade Estadual de Campinas, Brasil Frederico de Mello Brandão Tavares, Universidade Federal de Ouro Preto, Brasil Gabriela Reinaldo, Universidade Federal do Ceará, Brasil

Gilson Vieira Monteiro, Universidade Federal do Amazonas, Brasil Gustavo Daudt Fischer, Universidade do Vale do Rio dos Sinos, Brasi Itania Maria Mota Gomes, Universidade Federal da Bahia, Brasil Jiani Adriana Bonin, Universidade do Vale do Rio dos Sinos, Brasil José Afonso da Silva Junior, Universidade Federal de Pernambuco, Brasil José Luiz Aidar Prado, Pontifícia Universidade Católica de São Paulo, Brasi
Juçara Gorski Brittes, Universidade Federal de Ouro Preto, Brasil Juliana Freire Gutmann, Universidade Federal da Bahia, Brasil Laura Loguercio Cánepa, Universidade Anhembi Morumbi, Brasil Letícia Cantarela Matheus, Universidade do Estado do Rio de Janeiro, Brasil Liziane Soares Guazina, Universidade de Brasília, Brasil Luíza Mônica Assis da Silva, Universidade Católica de Brasília, Brasil Maria Ataide Malcher, Universidade Federal do Pará, Brasil Maria Elisabete Antonioli, Escola Superior de Propaganda e Marketing - SP, Brasil Maria das Graças Pinto Coelho, Universidade Federal do Rio Grande do Norte, Brasil Marcel Vieira Barreto Silva, Universidade Federal da Paraiba, Brasil Marcia Tondato, Escola Superior de Propaganda e Marketing, Brasil Marli Santos, Universidade Metodista de São Paulo, Brasil Márcio Souza Gonçalves, Universidade do Estado do Rio de Janeiro, Brasil Mauricio Mario Monteiro, Universidade Anhembi Morumbi, Brasil Mauricio Ribeiro da Silva, Universidade Paulista, Brasil Mauro de Souza Ventura, Universidade Estadual Paulista, Brasil Mayka Castellano, Universidade Federal Fluminense, Brasi Micael Maiolino Herschmann, Universidade Federal do Rio de Janeiro, Brasil Mozahir Salomão Bruck, Pontifícia Universidade Católica de Minas Gerais, Brasil Nísia Martins Rosario, Universidade Federal do Rio Grande do Sul, Brasil Potiguara Mendes Silveira Jr, Universidade Federal de Juiz de Fora, Brasil Rafael Grohmann, FIAM-FAAM - Centro Universitário, Brasil Raquel Ritter Longhi, Universidade Federal de Santa Catarina, Brasil Regiane Regina Ribeiro, Universidade Federal do Paraná, Brasil Roberto Elísio dos Santos, Universidade Municipal de São Caetano do Sul, Brasil Rodolfo Rorato Londero, Universidade Estadual de Londrina, Brasil Sérgio Luiz Gadini, Universidade Estadual de Ponta Grossa, Brasil Simone Maria Andrade Pereira de Sá, Universidade Federal Fluminense, Brasil Simone Maria Rocha, Universidade Federal de Minas Gerais, Brasil Suzana Reck Miranda, Universidade Federal de São Carlos, Brasil Tarcyanie Cajueiro Santos, Universidade de Sorocaba, Brasil Tatiana Oliveira Siciliano, Pontifícia Universidade Católica do Rio de Janeiro, Brasil Veneza Mayora Ronsini, Universidade Federal de Santa Maria, Brasil

\section{CONSELHO CIENTÍFICO}

Cristiane Freitas Gutfreind, Pontifícia Universidade Católica do Rio Grande do Sul, Brasil | Eduardo Antônio de Jesus, Universidade Federal de Minhas Gerais, Brasil | Eduardo Morettin, Universidade de São Paulo, Brasil I Irene de Araújo Machado, Universidade de São Paulo, Brasil I Miriam de Souza Rossini, Universidade Federal do Rio Grande do Sul, Brasil

\section{COMISSÃO EDITORIAL}

Eduardo Antonio de Jesus, Universidade Federal de Minas Gerais, Brasil I Igor Pinto Sacramento, Universidade Federal do Rio de Janeiro, Brasil I Kelly Cristina de Souza Prudencio, Universidade Federal do Paraná, Brasil I Osmar Gonçalves dos Reis Filho, Universidade Federal do Ceará, Brasil

\section{CONSULTORES AD HOC}

Cesar Augusto Baio Santos, Universidade Federal do Ceará, Brasil I Lilian França Universidade Federal de Sergipe, Brasil I Maria Aparecida Baccega, Escola Superior de Propaganda e Marketing, Brasil I Márcia Benetti, Universidade Federal do Rio Grande do Sul, Brasil I Miguel Serpa Pereira, Pontifícia Universidade Católica do Rio de Janeiro, Brasil | Renato Essenfelder, Escola Superior de Propaganda e Marketing, Brasil

\section{EQUIPE TÉCNICA}

ASSISTENTE EDITORIAL Márcio Zanetti Negrini | REVISÃO DE TEXTOS Melina Santos | EDITORAÇÃO ELETRÔNICA Roka Estúdio I IMAGEM DE CAPA Silas de Paula

COMPÓS I www.compos.org.br

Associação Nacional dos Programas de Pós-Graduação em Comunicação

Presidente

Marco Roxo

Programa de Pós-Graduação em Comunicação - UFF marcos-roxo@uol.com.br

Vice-Presidente Isaltina Gomes Programa de Pós-Graduação em Comunicação - UFPE isaltina@gmail.com

Secretária-Geral

Gisela Castro

Programa de Pós-Graduação em Comunicação e Práticas de Consumo - ESPM castro.gisela@gmail.com

CONTATO I revistaecompos@gmail.com 